\title{
Paradisiaca/Solanum Tuberosum Biowaste Composited with Graphene Oxide for Flexible Supercapacitor
}

\author{
Senthil Kumar Kandasamy ${ }^{1, *}$, Chandrasekaran Arumugam ${ }^{1}$, A S Sajitha ${ }^{2}$, Saggurthi Prabhakara Rao ${ }^{3}$, Sangavi Selvaraj ${ }^{1}$, \\ Ragavi Vetrivel ${ }^{1}$, Roobak Selvarajan ${ }^{1}$, Abeer Mohamed Alosaimi ${ }^{4}$, Anish Khan ${ }^{5,6}$, Mahmoud Ali Hussein ${ }^{5,7}$ \\ and Abdullah M. Asiri 5,6 \\ ${ }^{1}$ Department of Electronics and Communication Engineering, Kongu Engineering College, Erode, India. \\ ${ }^{2}$ Department of Chemical Engineering, Kongu Engineering College, Erode, India. \\ ${ }^{3}$ Department of Electronics and Communication Engineering, Joginpally B R Engineering College, Hyderabad, India \\ ${ }^{4}$ Department of Chemistry, Faculty of Science, Taif University, P.O. Box 11099, Ta'if 21944, Saudi Arabia \\ ${ }^{5}$ Chemistry Department, Faculty of Science, King Abdulaziz University, P.O. Box 80203, Jeddah 21589, Saudi Arabia \\ ${ }^{6}$ Center of Excellence for Advanced Materials Research, King Abdulaziz University, P.O. Box 80203, Jeddah 21589, Saudi \\ Arabia \\ ${ }^{7}$ Chemistry Department, Faculty of Science, Assiut University, Assiut, 71516 Egypt
}

*Corresponding Author Email: senthilkumar6k@gmail.com

\begin{abstract}
This work focuses on the development of a novel type of chemically activated carbon networks composited with the graphene oxide. Here, the carbon networks were derived from green biomass wastes such as orange peels, banana peels and potato starch. All the obtained carbon materials were being activated using different activating agents based on the higher specific capacitance such as phosphoric acid activated orange peel derived carbon, sulphuric acid activated banana peel derived carbon and hydrochloric acid activated potato starch. Further they were individually composited with graphene oxide for enhanced performance. Different chemical activation is employed for the sake of obtaining higher specific capacitance, energy and power density. Phosphoric acid activation on orange peel derived carbon network was selected due to the improvement in the micropores and further increased the surface area with the controlling capability of structures of activated carbon. To improve the conductivity of the samples, graphene oxide was added. The electrochemical performance of orange peel, banana peel and potato starch derived nano porous activated carbon materials composited with graphene oxide for supercapacitor applications is evaluated using aqueous $\mathrm{H}_{2} \mathrm{SO}_{4}$ electrolytes at a scan rate of $10 \mathrm{mV} \mathrm{s}$. . The samples that are prepared are structurally characterized using fourier transform infrared spectroscopy, $x$-ray diffraction and electrochemically characterized using cyclic voltammetry, galvanostatic charge and discharge measurements, and electrochemical impedance spectroscopy. From the electrochemical measurements, suitability of material as electrode for supercapacitors can be understood. The superior electrochemical performance is attributed in orange peel derived nano porous carbon/ graphene oxide due to porous structure.
\end{abstract}

Keywords: Biowaste composite, Citrus Sinensis Flavedos, Graphene Oxide, Flexible Supercapacitor, Musa Paradisiaca, Solanum Tuberosum

Received: October-25-2020, Accepted: January-13-2021, https://doi.org/10.14447/jnmes.v24i1.a04

\section{NOMENCLATURE}

$\mathrm{mV} \mathrm{s}^{-1} \quad$ millivolt/sec

FTIR fourier transform infrared spectroscopy

XRD $\quad$-ray diffraction

CV cyclic voltammetry

GCD galvanostatic charge and discharge

EIS electrochemical impedance spectroscopy

DC direct current

ESR equivalent series resistance

$\mathrm{m}^{2} \mathrm{~g}^{-1} \quad$ meter square per gram

$\mathrm{Ag}^{-1} \quad$ ampere per gram

\section{INTRODUCTION}

The fast utilization of fossil fuel with the worsening environment makes the necessity to develop a clean and novel energy storage system [1]. Among the devices, supercapacitor, fills the space between electrolytic capacitors and rechargeable batteries, and fascinated towards new consideration ascribed to its high power density and extended cycle life [2]. It can store huge amount of energy than the capacitors. Similarly, charging and discharging was happened in a pace manner than batteries, and they support without any degradation high charges and deep discharge cycles than rechargeable batteries. Supercapacitors are used for regenerative braking, short-term energy storage, etc. Supercapacitors are classified into electric double-layer capacitor (EDLC) and pseudocapacitor. A double layer is a structure that appears at the interface between the surface of an electrode and electrolyte.

Activated carbon (AC) derived from bountiful biomass is an ecological. As AC is broadly considered for supercapacitors, precursor optimization is crucial. When AC is developed from the banana peel without using the activating agents, it exhibited the specific surface area of $1084 \mathrm{~m}^{2} \mathrm{~g}^{-1}$ [3]. From [4], it was confirmed that the pore size of 40 to $50 \mathrm{~nm}$, is more constructive for ion transportation. Carbonization is an ecological pyrolytic reaction, and also exothermic. Carbonization takes place in drying phase, thermal decomposition, and cooling. By means of scalding heat, the biomaterial can be quickly carbonized, further turned into solid carbon. Some of the factors are affecting the charcoal yield such as heating rate, peak temperature, feedstock, gas environment, and pressure. Similarly, specific capacitances of carbonaceous materials are limited due to its structure. 
Senthil Kumar Kandasamy et al. / J. New Mat. Electrochem. Systems

By introducing citrate salts such as porogen, approximately, 20 times of surface area and 5 times of specific capacitance is observed [4]. Recently, graphene nanomaterials have gained more recognition in storage mechanism, owing to its distinctive properties [5]. In [6], porous nitrogen doped carbon were derived from citrus sinensis flavedos by carbonization and activation. The obtained carbon was activated with the help of sulphuric acid, the electrodes of OPC, OPCH, OPCP and OPCS in $0.5 \mathrm{M}$ $\mathrm{H}_{2} \mathrm{SO}_{4}$ aqueous electrolyte exhibit the specific capacitance of $39,28,92$ and $88 \mathrm{~F} \mathrm{~g}^{-1}$ respectively, with improved capacity retention ratio [6]. Graphene oxide was obtained through modified hummers' method [7]. The presence of defects in graphene oxide is well suited for the activated carbon.

Asymmetric supercapacitor was developed using orange peel as electrode, electrolyte and even separator [8]. It has been suggested that orange peel can be used as a precursor for the preparation of carbon nanosheets, which is used further for the growth of $\mathrm{MnO}_{2}$ nanorods over it [9]. $\mathrm{KOH}$ activation of orange peel derived nano carbon, exhibited 3dimensional interconnected pores with micro- and mesopores due to the presence of $\mathrm{KOH}$ [10]. The structure will provide short diffusion pathways for ions and fast ionic transport. Activated carbon is developed from orange peels [11] have been carbonized at a temperature of $600^{\circ} \mathrm{C}$ and activated using $\mathrm{KOH}$ at $700^{\circ} \mathrm{C}$ [12]. Owing to, increased surface area and porosity, activated carbon has affected the specific capacitance. Nitrogen doped activated carbon is synthesized from orange peels using simple chemical co-precipitation method with cycling stability up to 3500 cycles. Highly permeable Nitrogen doped activated carbon from orange peels showed the specific capacitance of $465 \mathrm{~F} \mathrm{~g}^{-1}$ at $10 \mathrm{mV}$ $\mathrm{s}^{-1}[13]$.

Orange peels may be useful for preparing catalyst for fuel cell and for synthesizing low-cost carbon for supercapacitors [14]. Orange peel based activated carbon is obtained with the specific capacitance of $56 \mathrm{Fg}^{-1}$ at $1 \mathrm{mVs}^{-1}$ [15]. Lead and carbon based hybrid supercapacitor obtained from orange peels exhibited $192 \mathrm{~F} \mathrm{~g}^{-1}$ at $10 \mathrm{~A} \mathrm{~g}^{-1}$ and also maintained the stability even after 10,000 cycles. With the help of B- doping and N-doping, hole density and carriers was getting improved, respectively [16]. Through the $\mathrm{N}$ - doping, wettability of the samples was increased, which further improve the specific capacitance. $\mathrm{NiCo}_{2} \mathrm{O}_{4}$ based asymmetric supercapacitor showed $100 \%$ capacity retention ratio till 8000 cycles and also exhibited the energy density of $32.08 \mathrm{Wh} \mathrm{kg}^{-1}$ at 700.43 $\mathrm{W} \mathrm{kg} \mathrm{kg}^{-1}$ in a $2 \mathrm{M} \mathrm{KOH}$. Higher porosity as well as doping facilitated the diffusion of electrolyte ions into the electroactive substance [17].

Symmetric supercapacitors was fabricated using $\mathrm{Ni}(\mathrm{OH})_{2}$ and $\mathrm{AC}$ in aqueous electrolyte [18]. By taking arrays of supercapacitor and power conversion efficiency into consideration, [19] projected a design. $\mathrm{MnO}_{2} / \mathrm{N}$-doped graphene composites were synthesized and due to the presence of excess $\mathrm{Mn}$, it is used to improve the charge transfer resistance and also concealed the ionic diffusion [20]. From the waste fiberboards N, O co-doped carbon dots were produced through acid etching method. After that, by means of hydrothermal method graphene hydrogels decorated with $\mathrm{N}$, O co-doped carbon dots were synthesized and optimal composite showed a specific capacitance of $335.1 \mathrm{~F} \mathrm{~g}^{-1}$ at 1 $\mathrm{A} \mathrm{g}^{-1}$ with the capacitance retention of $90.6 \%$ after 500 bending cycles [21]. Graphene-based materials for supercapacitors were proposed [22], with different properties.
By the inclusion of silica in corn starch derived polymer electrolyte, the ionic conductivity with respect to temperature and EDLC capacitance were improved [23]. The fibers obtained from Empty Fruit Bunch of palm oil are used to produce porous carbon electrodes [24]. By modifying the pure graphite paper through exfoliation, foam-like structured graphite paper was obtained [25]. Because of the modified with micro, meso and macro pores, $\mathrm{AC}$ is prepared by steam activation using pine nut shell [26]. Porous carbons were prepared using cycas leaves as a major precursor [27]. Similarly, AC was synthesized from waste corn cob by ultrasonic assisted chemical and physical activation [28]. Potassium carbonate was used as an activating agent for preparing activated carbon from citrus peel [29]. Electrolye accessibility can be improved with the interconnected porous nature which further stirred the globular $\mathrm{NiCO}_{2} \mathrm{O}_{4}$ formation, without any aggregation [30]. Using the husks of cottonseed, 3-dimensional honeycomb porous carbon was synthesized by $\mathrm{KOH}$ activation [31]. A higher specific capacitance of 479.29 $\mathrm{F} \mathrm{g}^{-1}$ is observed for activated hard carbon [32]. Bamboo fibers were carbonized for temperature dependent energy storage applications [33].

[34] proposed a model for activated carbon based electrode from the banana peel for supercapacitor with the specific surface area, specific capacitance, energy density and power density of $581 \mathrm{~m}^{2} \mathrm{~g}^{-1}, 68 \mathrm{~F} \mathrm{~g}^{-1}, 0.75 \mathrm{Wh} \mathrm{kg}^{-1}$ and $31 \mathrm{~W} \mathrm{~kg}^{-1}$, respectively. Binder-free porous carbon electrodes derived from banana peel possessed suitable mesopores and hydrophilicity [35]. Sulphur doped banana peel-derived activated carbon was effectively synthesized with highest surface area [36]. By chemical co-precipitation biochar is obtained from banana peel and it has been mixed with $\mathrm{SnO}_{2}$ and acted as electrode with $465 \mathrm{~F} \mathrm{~g}^{-1}$ of specific capacitance [37]. $\mathrm{ZnCl}_{2}$ and $\mathrm{KOH}$ were used as pore forming substance on carbon. Using these substances, activated carbon obtained from banana fibers was activated for the purpose of improving the surface area and electrochemical performance [38]. Biopolymers presented in the cell walls of banana peel can attract ions. Zinc complexes similar to metal-organic frameworks were formed on the surface of the pores [39]. Coconut shells have high lignocellulosic content could be converted into activated carbon [40]. Good value of specific capacitance is observed for smaller particles of pepper shell based activated carbon electrodes [41].

In general, the carbonized temperature for banana peels is $600^{\circ} \mathrm{C}$ and mainly it can be activated using $\mathrm{KOH}$ [42]. Through stabilization and carbonization followed by chemical activation, microporous potato starch-based activated carbon spheres with the SSA of $2342 \mathrm{~m}^{2} \mathrm{~g}^{-1}$ were synthesized and by changing the carbonization temperature and $\mathrm{KOH}$ /potato carbon sphere ratio textural properties were modified [43]. Using natural potato starch and iron nitrate, $\mathrm{AC}$ was derived and performed as a substrate for in-situ growth of carbon nanofibers [44]. Using solution cast technique, an electrolyte can be prepared from potato starch is a promising candidate for electrochemical devices [45]. Biodegradable polymer electrolyte obtained from the combination of potato starch and $\mathrm{MgCl}_{2}$ [46]. Starch-based electrolytes are very promising candidate for flexible supercapacitor [47]. Mesoporous activated carbon spheres were derived from starch of the potato through $\mathrm{CO}_{2}$ activation [48].

This research is concentrated on inexpensive and effortlessly synthesized biomass derived activated 
carbon/graphene oxide composite and to investigating the outlook of applying biomass derived activated carbon/graphene oxide based electrodes for the electrochemical energy-storage. Three varieties of biomass activated carbon/graphene oxide composite were synthesized from citrus sinensis flavedos activated carbon/graphene oxide composite (OPC), musa paradisiaca activated carbon/graphene oxide composite (BPC), and solanum tuberosum activated carbon/graphene oxide composite (POC) through carbonization, activation and modified hummers' method and tested as supercapacitor electrodes. Structural characterizations such as XRD and FTIR were done for graphene oxide, citrus sinensis flavedos/ graphene oxide, Musa Paradisiacal graphene oxide, Solanum Tuberosum/ graphene oxide. Similarly, electrochemical analysis such as CV, GCD and EIS were done for for graphene oxide, citrus sinensis flavedos/ graphene oxide, Musa Paradisiacal graphene oxide, Solanum Tuberosum/graphene oxide.

\section{EXPERIMENTAL SECTION}

\section{Materials}

Graphite was purchased from Aksharchem, sodium nitrate and potassium permanganate were obtained from Merck, hydrogen peroxide and hydrochloric acid were obtained from Nice chemicals private limited and concentrated sulphuric acid was from RFCL limited. Phosphoric acid was obtained from Sigma Aldrich.
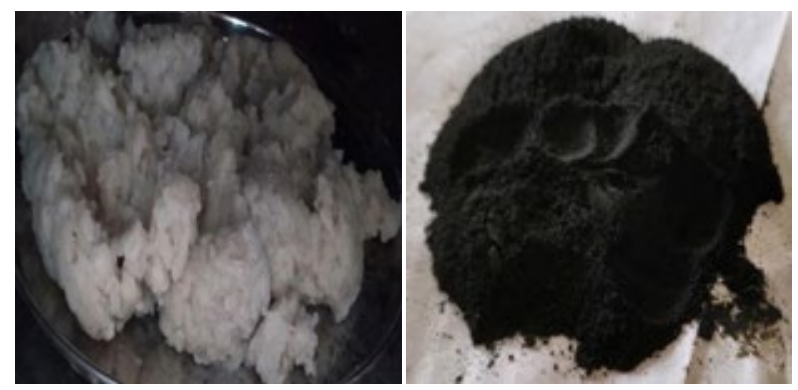

Figure 1. Dried orange peels, banana peels, potato starch and derived activated carbon

Fresh orange fruits (Citrus Sinensis), banana peels (Musa Paradisiaca) and potato (Solanum Tuberosum) were purchased from local shop located in Tirupur, Tamilnadu, India.

\section{Preparation of Activated Carbon from Citrus Sinensis Flavedos}

The flavedos of citrus sinensis were initially removed manually and they were dried at room temperature of about $25^{\circ} \mathrm{C}$ for 7 days. Hence the oil in the sacs became arid. The flavedos were then completely washed with distilled water and the albedos were ridded using peelers and razors. The de-albedo peels were then cut into small squares. They were again dried at room temperature for 24 hours. Then, the peels were kept in the hot air oven at $90^{\circ} \mathrm{C}$ for 24 hours. The further process was accomplished by consigning the peels to sigma high temperature furnace with the temperature were maintained at $600^{\circ} \mathrm{C}$ for 2 hours. They were then allowed to cool down for about 20 hours. They were then taken out and crushed into powder with the help of plunger. As a result, the carbon is extracted, which is the source material for the electrodes. Followed by the preparation it was activated using phosphoric acid. Figure 1 shows the dried orange peels, banana peels, potato starch and derived activated carbon.

\section{Preparation of Activated Carbon from Musa Paradisiaca}

Banana peel was dried at room temperature for 4 days. After that it was completely washed with distilled water and removed the juicy inner skin. Then it was cut into small pieces and again dried at the same temperature for 1 day. To remove the moisture content, further it was kept in a hot air oven at $90^{\circ} \mathrm{C}$ for 2 days. Then it was grounded by pestle and mortar. Finally, demoisturized pieces of banana peel were placed in a furnace and maintained the temperature at $600^{\circ} \mathrm{C}$ for 2 hours. They were again crushed into powder by plunger. Followed by this, it was activated using sulphuric acid.

\section{Preparation of Activated Carbon from Solanum Tuberosum}

Initially $1.7 \mathrm{~kg}$ of solanum tuberosum was peeled of using razors, boiled for 6 hours in medium flame and then it was smashed using hand and kept it overnight at room temperature. Then it was kept in an oven for about 48 hours. The further process was done by consigning the starch in sigma high temperature furnace and the temperature was maintained at $600^{\circ} \mathrm{C}$ for 2 hours. They were taken out and crushed into powder. Followed by the preparation of potato derived carbon it was activated using hydrochloric acid. The activated samples were then oven dried for about 8 hours.

\section{Synthesis of Graphene Oxide/Biomass Derived Activated Carbon Composite}

Graphene oxide (GO) was prepared from graphite through modified hummers' method. Initially, 1.2 gram of graphene oxide and ethylene glycol were mixed and stirred in a magnetic stirrer for 30 minutes, succeeding that, 0.6 gram of orange peel derived carbon was added to stirrer and the process took place for about 30 minutes. The same stirring process was carried out for banana derived carbon and potato derived carbon. After that, the mixture was filtered using whatman filter paper and the obtained colloidal mixture was oven dried. After 24 hours, different composites were obtained by centrifugation such as citrus sinensis flavedos derived activated carbon / Graphene Oxide, Musa Paradisiaca derived activated carbon / Graphene Oxide, Solanum Tuberosum derived activated carbon / Graphene Oxide and named it as OPC, BPC, POC, respectively.

\section{Material Characterization Methods}

FTIR spectroscopy measurements of GO, OPC, BPC and POC were analyzed by $\mathrm{KBr}$ method. Similarly, XRD results 
Senthil Kumar Kandasamy et al. / J. New Mat. Electrochem. Systems

of GO, OPC, BPC and POC were analyzed. The electrochemical analysis (CV, GCD, and EIS) of GO, OPC, $\mathrm{BPC}$ and POC were performed using Electrochemical Workstation (OrigaLys). There are three electrodes in the workstation namely, $\mathrm{Pt}$ Counter electrode, $\mathrm{Ag} / \mathrm{AgCl}$ Reference electrode and GO, OPC, BPC and POC based working electrode. To analyze the electrochemical nature of above said samples in $0.5 \mathrm{M} \mathrm{H}_{2} \mathrm{SO}_{4}$ electrolyte, prepared the electrode using the composite, mixed with polyvinyl acetate, surface activated rubber, water and dispersion agent, in the weight ratio of (60:40). Approximately, $200 \mu \mathrm{g}$ of samples was coated on the graphite rod. Finally, the electrodes were dried at $20^{\circ} \mathrm{C}$ for the period of 30 minutes. The electrochemical nature of composite was tested within a range of -1 to $1 \mathrm{~V}$.

\section{RESULTS AND DISCUSSION}

FTIR analysis of GO, OPC, BPC and POC were done over a range of 400 to $4000 \mathrm{~cm}^{-1}$ to understand the chemical structure of the composite. Fig. 2 shows the FTIR spectra of GO, OPC, BPC and POC. From the spectra of GO, a strong peak is observed at $1410 \mathrm{~cm}^{-1}$. For OPC, the broad band around $3600 \mathrm{~cm}^{-1}$ was observed due to hydroxyl stretching vibrations of lignin and carbohydrates. The band at $1692 \mathrm{~cm}^{-1}$ was ascribed to $\mathrm{C}=\mathrm{O}$ stretching band of carboxyl groups. The peak at $3741 \mathrm{~cm}^{-1}$, was higher than the peak at $3570 \mathrm{~cm}^{-1}$ ascribed to increased hydroxyl groups on the surface area after chemical activation. The band at $1410 \mathrm{~cm}^{-1}$ corresponds to intensity of hydroxyl group. Further analyzing the BPC, it was identified that, compared to $\mathrm{HCl}$ and $\mathrm{H}_{3} \mathrm{PO}_{4}, \mathrm{H}_{2} \mathrm{SO}_{4}$ based chemical activation influenced the FTIR analysis. It showed a strong peak at $3697.24 \mathrm{~cm}^{-1}$ corresponds to the hydroxyl stretching vibrations. The peak at $1598.77 \mathrm{~cm}^{-1}$ is assigned to $\mathrm{C}=\mathrm{O}$ stretching band. From the FTIR spectra of POC, the highest peak is observed at $1410 \mathrm{~cm}^{-1}$ corresponds

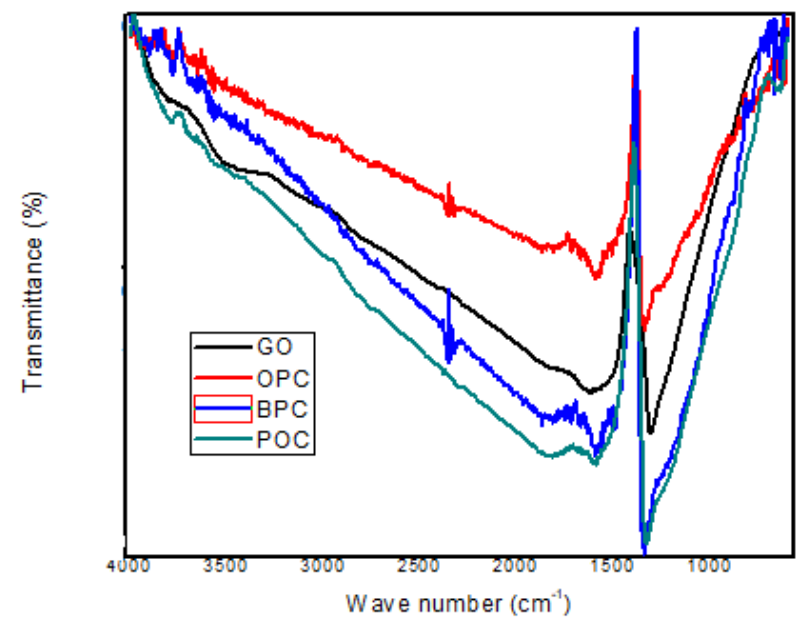

Figure 2. FTIR spectra of GO, OPC, BPC and POC

to intensity of hydroxyl group. Similarly, the peak at $1590.12 \mathrm{~cm}^{-1}$ is assigned to $\mathrm{C}=\mathrm{O}$ stretching band. There is a synergistic effects between GO and bio-wastes of citrus sinensis flavedos, Musa Paradisiaca and Solanum Tuberosum.

X-ray diffraction is used to determine crystallographic disorder, as well as specifies the crystalline and amorphous nature of the prepared materials. Fig. 3 shows the XRD graphs for GO, OPC, BPC and POC. From the spectra, it was concluded that all the samples exhibited amorphous nature. Sample's amorphous nature supported the level of absorbance owing to its surface area and better number of active sites [49]. From the peak position of GO, it was observed that the samples OPC and POC were shifted to lower theta value. This may due to the expansion in their lattice volume or lattice parameters because of crystal minimization to a nanoscale range as well as the involved dopants and d values have increased. Similarly, it was found that, BPC was shifted to higher angle, which ascribed to decreased $d$ value and because of change in binding energy and change in mechanical properties. From the results of XRD of GO, it was observed that the recurrence of diffraction lines $\mathrm{C}(002)$ at $2 \theta=27^{\circ}$, which confirms the typical structure of GO. The peaks are still observed at $2 \theta=$ $36.8^{\circ}, 43.7^{\circ}$ and $56.4^{\circ}$ which suggests that the GO is not fully interconnected with oxygen atoms [50]. The attribute of cellulosic component observed at $42^{\circ}$ [51]. Sharp peak was observed at $27^{\circ}$ for the BPC indicating the crystalline region.

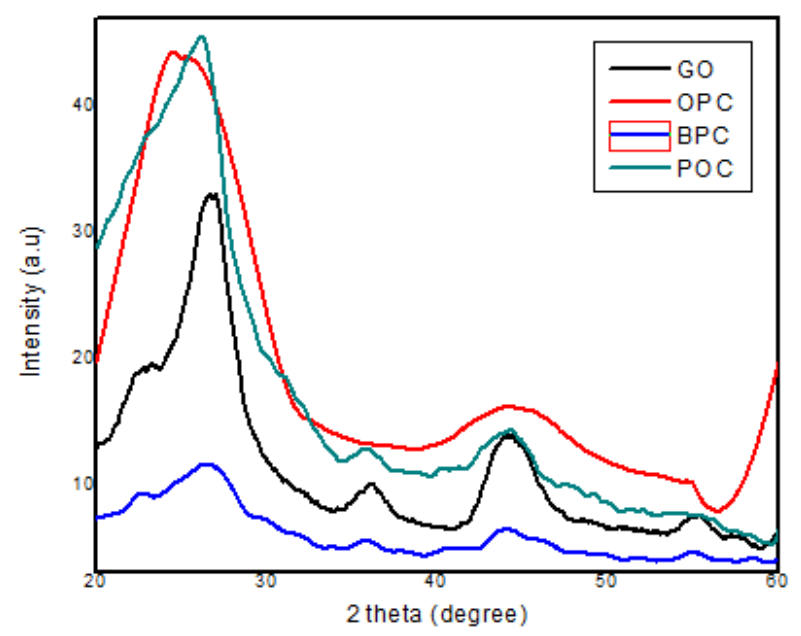

Figure 3. XRD spectra of GO, OPC, BPC and POC

XRD patterns of all the samples such as OPC, BPC, POC, reflected the chemical activation and carbonization process did not disrupt crystalline cellulose.

$\mathrm{CV}$ is used to exemplify the electrochemical activities and to compute the specific capacitance of the prepared samples. Fig. 4 shows the CV curves of GO, OPC, BPC and POC at scan rate of $10 \mathrm{mV} \mathrm{s}^{-1}$ within a potential window of -1 to $1 \mathrm{~V}$ in $0.5 \mathrm{M} \mathrm{H}_{2} \mathrm{SO}_{4}$ solution. From the previous works, phosphoric acid activated orange peel derived carbon, sulphuric acid activated banana peel derived carbon and hydrochloric acid activated potato starch based carbon were the preferred choice. It is ascribed that the $\mathrm{CV}$ curve exhibited nearly ideal rectangular shape in the mid region, demonstrating that capacitance value mainly initiates from the EDL based on adsorption/desorption of ions. In that case, all the above said samples were treated using phosphoric acid, sulphuric acid, and hydrochloric acid. Rectangular curve is the response of an ideal supercapacitor. A small amount of pseudocapacitance is observed for biomass composite materials. The specific capacitances are measured as 48.18 , 90.23, 75.82 and $28.27 \mathrm{~F} \mathrm{~g}^{-1}$ respectively, corresponding to GO, OPC, BPC and POC. Among the samples, OPC exhibited better specific capacitance. The specific capacitances for all the samples are tabulated in Table 1 . 
Table 1. Specific capacitance of samples obtained from CV analysis for various activation agents

\begin{tabular}{|l|c|c|c|c|}
\hline \multicolumn{1}{|c|}{$\begin{array}{l}\text { Activation } \\
\text { Agents } \\
\text { Samples }\end{array}$} & $\begin{array}{l}\text { No } \\
\text { activation }\end{array}$ & $\mathrm{H}_{2} \mathrm{SO}_{4}$ & $\mathrm{H}_{3} \mathrm{PO}_{4}$ & $\mathrm{HCl}$ \\
\hline $\begin{array}{l}\text { Citrus } \\
\text { Sinensis } \\
\text { Flavedos }\left(\mathrm{Fg} \mathrm{g}^{-1}\right)\end{array}$ & 39 & 88 & 92 & 28 \\
\hline $\begin{array}{l}\text { Musa } \\
\text { Paradisiaca }\left(\mathrm{Fg}^{-1}\right)\end{array}$ & 148.7 & 306.2 & 9.52 & 256.8 \\
\hline $\begin{array}{l}\text { Solanum } \\
\text { Tuberosum }\left(\mathrm{Fg} \mathrm{g}^{-1}\right)\end{array}$ & 19 & 59 & 19 & 94 \\
\hline GO $\left(\mathrm{Fg} \mathrm{g}^{-1}\right)$ & 48.18 & - & - & - \\
\hline OPC $\left(\mathrm{Fg} \mathrm{g}^{-1}\right)$ & - & - & 90.23 & - \\
\hline BPC $\left(\mathrm{F} \mathrm{g} \mathrm{g}^{-1}\right)$ & - & 75.82 & - & - \\
\hline POC $\left(\mathrm{Fg} \mathrm{g}^{-1}\right)$ & - & - & - & 28.27 \\
\hline
\end{tabular}

Table 2. Specific capacitance of samples obtained from GCD analysis at $0.025 \mathrm{~mA} \mathrm{~g}^{-1}$ for various activation agents

\begin{tabular}{|l|c|c|c|c|}
\hline \multicolumn{1}{|c|}{$\begin{array}{c}\text { Activation } \\
\text { Agents } \\
\text { Samples }\end{array}$} & $\begin{array}{l}\mathrm{No} \\
\text { activation }\end{array}$ & $\mathrm{H}_{2} \mathrm{SO}_{4}$ & $\mathrm{H}_{3} \mathrm{PO}_{4}$ & $\mathrm{HCl}$ \\
\hline $\begin{array}{l}\text { Citrus } \\
\text { Sinensis } \\
\text { Flavedos }\left(\mathrm{Fg} \mathrm{g}^{-1}\right)\end{array}$ & 72 & 50 & 59 & 65 \\
\hline $\begin{array}{l}\text { Musa } \\
\text { Paradisiaca }\left(\mathrm{Fg}^{-1}\right)\end{array}$ & 67 & 56 & 15 & 182 \\
\hline $\begin{array}{l}\text { Solanum } \\
\text { Tuberosum }\left(\mathrm{Fg} \mathrm{g}^{-1}\right)\end{array}$ & 32 & 74 & 82 & 56 \\
\hline GO $\left(\mathrm{F} \mathrm{g}^{-1}\right)$ & 244 & - & - & - \\
\hline OPC $\left(\mathrm{Fg} \mathrm{g}^{-1}\right)$ & - & - & 78 & - \\
\hline BPC $\left(\mathrm{Fg} \mathrm{g}^{-1}\right)$ & - & 90 & - & - \\
\hline POC $\left(\mathrm{Fg} \mathrm{g}^{-1}\right)$ & - & - & - & 260 \\
\hline
\end{tabular}

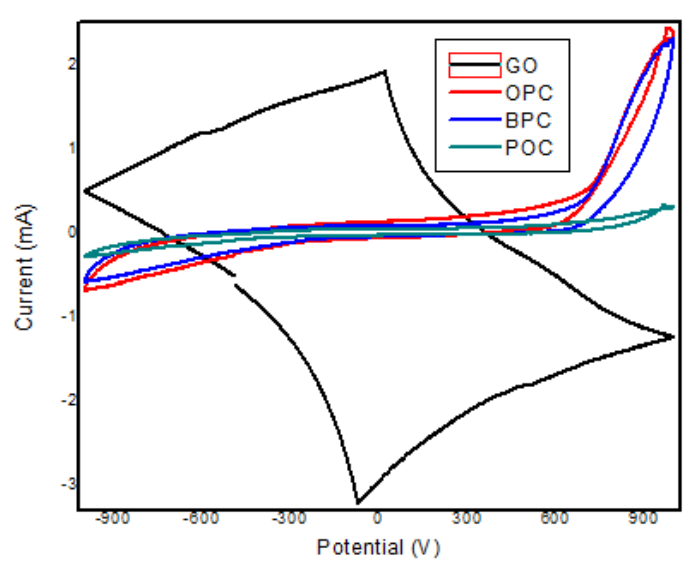

Figure 4. $\mathrm{CV}$ analysis of GO, OPC, BPC and POC
Table 3. Specific capacitance of samples obtained from GCD analysis $0.05 \mathrm{~mA} \mathrm{~g}^{-1}$ for various activation agents

\begin{tabular}{|c|c|c|c|c|}
\hline $\begin{array}{c}\text { Activation } \\
\text { Agents } \\
\text { Samples }\end{array}$ & $\begin{array}{c}\text { No } \\
\text { activation }\end{array}$ & $\mathrm{H}_{2} \mathrm{SO}_{4}$ & $\mathrm{H}_{3} \mathrm{PO}_{4}$ & $\mathrm{HCl}$ \\
\hline $\begin{array}{c}\text { Citrus } \\
\text { Sinensis } \\
\text { Flavedos }\left(\mathrm{F} \mathrm{g}^{-1}\right)\end{array}$ & 67 & 51 & 64 & 47 \\
\hline $\begin{array}{c}\text { Musa } \\
\text { Paradisiaca }\left(\mathrm{F} \mathrm{g}^{-1}\right)\end{array}$ & 66 & 148 & 91 & 75 \\
\hline $\begin{array}{c}\text { Solanum } \\
\text { Tuberosum }\left(\mathrm{F} \mathrm{g} \mathrm{g}^{-1}\right)\end{array}$ & 58 & 74 & 70 & 40 \\
\hline GO $\left(\mathrm{F} \mathrm{g}^{-1}\right)$ & 230 & - & - & - \\
\hline OPC $\left(\mathrm{F} \mathrm{g} \mathrm{g}^{-1}\right)$ & - & - & 107 & - \\
\hline BPC $\left(\mathrm{F} \mathrm{g} \mathrm{g}^{-1}\right)$ & - & 162 & - & - \\
\hline POC $\left(\mathrm{F} \mathrm{g} \mathrm{g}^{-1}\right)$ & - & - & - & 224 \\
\hline
\end{tabular}

Further to analyze the capacitive performance of GO, OPC, $\mathrm{BPC}$ and $\mathrm{POC}$, its electrochemical properties are analysed at $0.025 \mathrm{~mA} \mathrm{~g}^{-1}$ using GCD measurement. The GCD curves are shown in Fig. 4. Approximate triangular shaped curves are with almost zero IR drop was observed for OPC, BPC and POC, except GO due to the aggregation. The specific capacitances are calculated as 244, 78, 90 and $260 \mathrm{~F} \mathrm{~g}^{-1}$ for GO, OPC, BPC and POC. Even though POC exhibited higher ESR and charge transfer resistance, the higher specific capacitance is observed for POC electrodes. From Table 2 to Table 7, the specific capacitances for all the samples are tabulated for different current density. From the Table 2, composite of $\mathrm{GO} / \mathrm{HCl}$ activated carbon derived from solanum tuberosum feasibly considered for low-cost for electrochemical applications as an electrode.
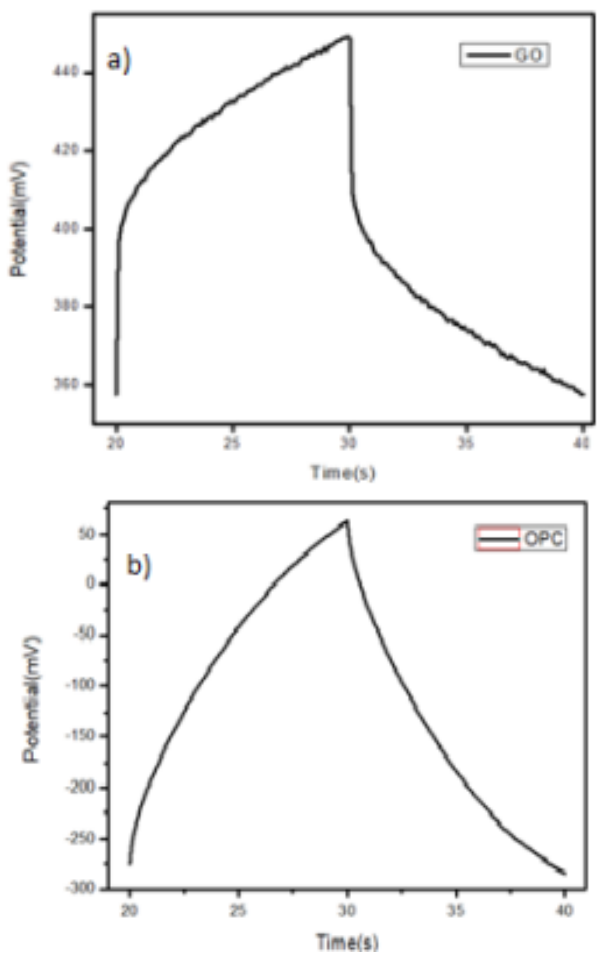
Senthil Kumar Kandasamy et al. / J. New Mat. Electrochem. Systems
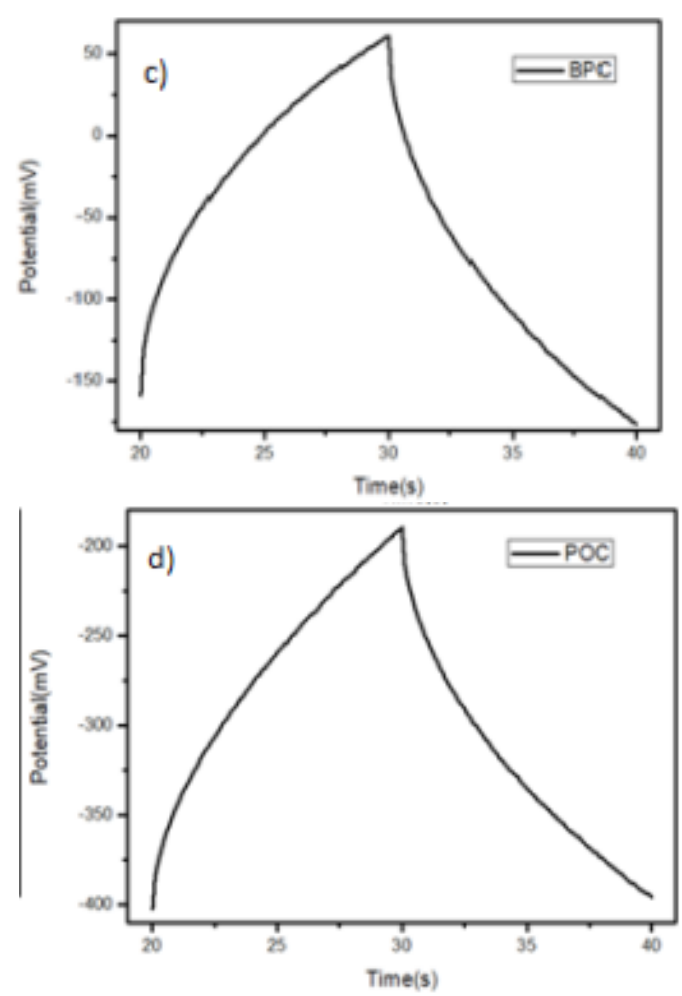

Figure 5. GCD spectra of GO, OPC, BPC and POC at $0.025 \mathrm{~mA} \mathrm{~g}^{-1}$

To further look into the ion diffusion and transport kinetics, electrochemical impedance spectroscopy has been employed. EIS analysis is the most important technique to learn the elementary behavior of electrodes. The nyquist spectrum is shown in Fig. 5 for the frequency ranges from $100 \mathrm{kHz}$ to 0.1 $\mathrm{Hz}$ using OrigaLys electrochemical workstation. $\mathrm{R}_{\mathrm{s}}$ and $\mathrm{R}_{\mathrm{ct}}$ values of the samples are tabulated in Table $6 \& 7$.

Table 4. Specific capacitance of samples obtained from GCD analysis $0.25 \mathrm{~mA} \mathrm{~g}^{-1}$ for various activation agents

\begin{tabular}{|l|c|c|c|c|}
\hline $\begin{array}{l}\text { Activation } \\
\text { Agents }\end{array}$ & $\begin{array}{l}\text { No } \\
\text { activation }\end{array}$ & $\mathrm{H}_{2} \mathrm{SO}_{4}$ & $\mathrm{H}_{3} \mathrm{PO}_{4}$ & $\mathrm{HCl}$ \\
Samples & 63 & 47 & 77 & 33 \\
\hline $\begin{array}{l}\text { Citrus } \\
\text { Sinensis } \\
\text { Flavedos }\left(\mathrm{Fg}^{-1}\right)\end{array}$ & 70 & 60 & 23 & 65 \\
\hline $\begin{array}{l}\text { Musa } \\
\text { Paradisiaca }\left(\mathrm{Fg}^{-1}\right)\end{array}$ & 78 & 73 & 47 & 29 \\
\hline $\begin{array}{l}\text { Solanum } \\
\text { Tuberosum }\left(\mathrm{Fg}^{-1}\right)\end{array}$ & 214 & - & - & - \\
\hline $\mathrm{GO}\left(\mathrm{Fg} \mathrm{g}^{-1}\right)$ & - & - & 138 & - \\
\hline OPC $\left(\mathrm{Fg} \mathrm{g}^{-1}\right)$ & - & 117 & - & - \\
\hline BPC $\left(\mathrm{Fg} \mathrm{g}^{-1}\right)$ & - & - & - & 190 \\
\hline POC $\left(\mathrm{Fg} \mathrm{g}^{-1}\right)$ & & & \\
\hline
\end{tabular}

Table 5. Specific capacitance of samples obtained from GCD analysis $0.5 \mathrm{~mA} \mathrm{~g}^{-1}$ for various activation agents

\begin{tabular}{|c|c|c|c|c|}
\hline $\begin{array}{c}\text { Activation } \\
\text { Agents } \\
\text { Samples }\end{array}$ & $\begin{array}{c}\text { No } \\
\text { activation }\end{array}$ & $\mathrm{H}_{2} \mathrm{SO}_{4}$ & $\mathrm{H}_{3} \mathrm{PO}_{4}$ & $\mathrm{HCl}$ \\
\hline $\begin{array}{c}\text { Citrus } \\
\begin{array}{c}\text { Sinensis } \\
\text { Flavedos }\left(\mathrm{Fg}^{-1}\right)\end{array}\end{array}$ & 52 & 35 & 169 & 19 \\
\hline $\begin{array}{c}\text { Musa } \\
\text { Paradisiaca }\left(\mathrm{F} \mathrm{g}^{-1}\right)\end{array}$ & 79 & 57 & 12 & 53 \\
\hline $\begin{array}{c}\text { Solamum } \\
\text { Tuberosum }\left(\mathrm{Fg}^{-1}\right)\end{array}$ & 67 & 71 & 24 & 21 \\
\hline GO $\left(\mathrm{Fg} \mathrm{g}^{-1}\right)$ & 182 & - & - & - \\
\hline OPC $\left(\mathrm{Fg} \mathrm{g}^{-1}\right)$ & - & - & 212 & - \\
\hline BPC $\left(\mathrm{Fg} \mathrm{g}^{-1}\right)$ & - & 98 & - & - \\
\hline POC $\left(\mathrm{Fg} \mathrm{g}^{-1}\right)$ & - & - & - & 172 \\
\hline
\end{tabular}

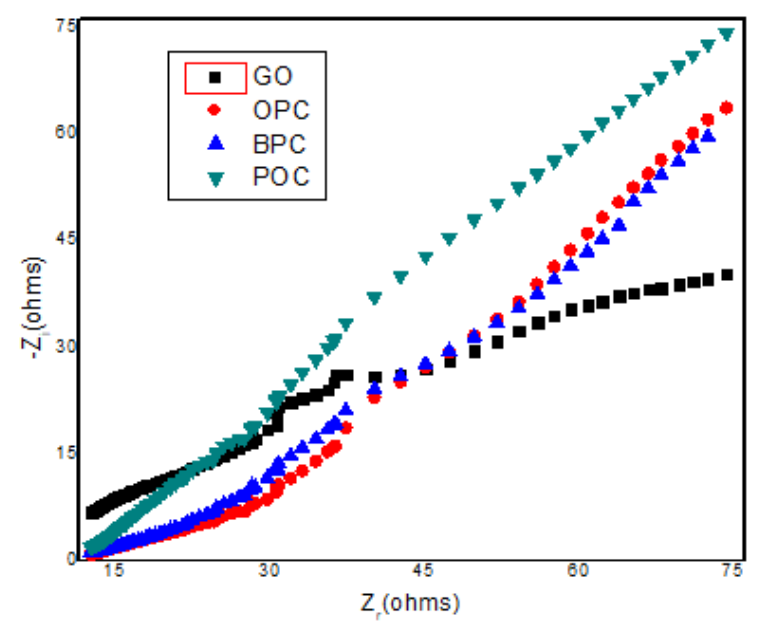

Figure 6. EIS analysis of GO, OPC, BPC and POC

Table 6. ESR of samples obtained from EIS analysis

\begin{tabular}{|l|c|c|c|c|}
\hline $\begin{array}{l}\text { Activation } \\
\text { Agents } \\
\text { Samples }\end{array}$ & $\begin{array}{l}\text { No } \\
\text { activation }\end{array}$ & $\mathrm{H}_{2} \mathrm{SO}_{4}$ & $\mathrm{H}_{3} \mathrm{PO}_{4}$ & $\mathrm{HCl}$ \\
\hline $\begin{array}{l}\text { Citrus } \\
\text { Sinensis } \\
\text { Flavedos }\left(\mathrm{Fg} \mathrm{g}^{-1}\right)\end{array}$ & 1.08 & 61.15 & 39.09 & 87.9 \\
\hline $\begin{array}{l}\text { Musa } \\
\text { Paradisiaca }\left(\mathrm{Fg} \mathrm{g}^{-1}\right)\end{array}$ & 1.2 & 0.1 & 1.3 & 0.2 \\
\hline $\begin{array}{l}\text { Solanum } \\
\text { Tuberosum }\left(\mathrm{F} \mathrm{g}^{-1}\right)\end{array}$ & 2.1 & 0.8 & 97.4 & 10.68 \\
\hline GO $\left(\mathrm{Fg} \mathrm{g}^{-1}\right)$ & 13.19 & - & - & - \\
\hline OPC $\left(\mathrm{Fg} \mathrm{g}^{-1}\right)$ & - & - & 5.52 & - \\
\hline BPC $\left(\mathrm{F} \mathrm{g} \mathrm{g}^{-1}\right)$ & - & 8.52 & - & - \\
\hline POC $\left(\mathrm{F} \mathrm{g} \mathrm{g}^{-1}\right)$ & - & - & - & 12.62 \\
\hline
\end{tabular}


Table 7. Charge transfer resistance of samples obtained from EIS analysis

\begin{tabular}{|l|c|c|c|c|}
\hline $\begin{array}{l}\text { Activation } \\
\text { Agents } \\
\text { Samples }\end{array}$ & $\begin{array}{l}\text { No } \\
\text { activation }\end{array}$ & $\mathrm{H}_{2} \mathrm{SO}_{4}$ & $\mathrm{H}_{3} \mathrm{PO}_{4}$ & $\mathrm{HCl}$ \\
\hline $\begin{array}{l}\text { Citrus } \\
\text { Sinensis } \\
\text { Flavedos }\left(\mathrm{Fg} \mathrm{g}^{-1}\right)\end{array}$ & 1.08 & 61.15 & 39.09 & 87.9 \\
\hline $\begin{array}{l}\text { Musa } \\
\text { Paradisiaca }\left(\mathrm{F} \mathrm{g}^{-1}\right)\end{array}$ & 1.2 & 0.1 & 1.3 & 0.2 \\
\hline $\begin{array}{l}\text { Solanum } \\
\text { Tuberosum }\left(\mathrm{Fg} \mathrm{g}^{-1}\right)\end{array}$ & 2.1 & 0.8 & 97.4 & 10.68 \\
\hline GO $\left(\mathrm{Fg} \mathrm{g}^{-1}\right)$ & 13.19 & - & - & - \\
\hline OPC $\left(\mathrm{Fg} \mathrm{g}^{-1}\right)$ & - & - & 5.52 & - \\
\hline BPC $\left(\mathrm{Fg} \mathrm{g}^{-1}\right)$ & - & 8.52 & - & - \\
\hline POC $\left(\mathrm{F} \mathrm{g}^{-1}\right)$ & - & - & - & 12.62 \\
\hline
\end{tabular}

From the $\mathrm{R}_{\mathrm{ct}}$ values, better ion transport is observed for citrus sinensis flavedos derived activated carbon/graphene oxide composite. All the samples exhibited the linear curve in the low frequency region, corresponds to excellent capacitive performance. When compared to GO, the entire biomass composite exhibited lower equivalent series resistance suggested the high conductivity of the samples. Similarly, when compared to activated carbon derived from citrus sinensis flavedos, Musa Paradisiaca and Solanum Tuberosum, all the composite exhibited very small $\mathrm{R}_{\mathrm{s}}$, which may be due to the presence of optimum pore structure and enough charge transport as well as synergistic effect between GO and biomass. From the analysis, high conductivity is observed for OPC.

Phosphoric acid activation on orange peel derived carbon network was selected due to the improvement in the micropores and further increased the surface area with the controlling capability of structures of activated carbon. Hydrochloric acid activation on potato starch derived carbon was chosen due to the highest specific capacitance compared to sulphuric and phosphoric acid activation. Similarly, sulphuric acid activation on banana peel derived carbon was considered owing to its highest specific capacitance and lowest equivalent series resistance [53].

\section{CONCLUSION}

Biomass derived carbons have been prepared by carbonization and activation. This work is focused on the preparation of a chemically activated carbon networks composited with the graphene oxide. In this study, phosphoric acid activated orange peel derived carbon, sulphuric acid activated banana peel derived carbon and hydrochloric acid activated potato starch was considered. Finally, they were individually composited with graphene oxide for analyzing the specific capacitance. The samples that are prepared are structurally characterized using FTIR, $\mathrm{XRD}$ and electrochemically characterized using CV, GCD, and EIS. Phosphoric acid activated orange peel derived carbon demonstrated higher specific capacitance due to the level of micropores with increased surface area and with its controlling capability of structures of activated carbon. Further, to improve the conductivity, graphene oxide was added was added with the activated carbon networks. An outstanding electrochemical show demonstrated may be due to the electronic conductivity, surface area and porous volume.

The electrochemical analysis of orange peel, banana peel and potato starch derived nano porous activated carbon materials composited with graphene oxide is evaluated using $\mathrm{H}_{2} \mathrm{SO}_{4}$ electrolytes at a scan rate of $10 \mathrm{mV} \mathrm{s}^{-1}$. From the electrochemical measurements, suitability of material as electrode for supercapacitors can be understood. The superior electrochemical performance is attributed in orange peel derived nano porous carbon/graphene oxide composite due to porous structure. Among the samples listed above, OPC exhibited better electrochemical performance suited for supercapacitor application. OPC showed the specific capacitance value up to $90.23 \mathrm{~F} \mathrm{~g} \mathrm{~g}^{-1}$ at $10 \mathrm{mV} \mathrm{s}^{-1}$. The phosphoric acid activated carbon composited with graphene oxide may be acted as a capable candidate for modest design of high-performance supercapacitor. Several encouraged studies should be paying attention on the reuse of cheap, feasible biowastes for upcoming energy storage technology. The activated carbon prepared from orange peel showed a good performance, so usage of these carbons as alternative will results in great advantage. In future it is possible to infuse low quantity of inorganic chemicals with this orange peel derived carbon to enhance its electrochemical conductivity.

\section{ACKNOWLEDGMENT}

The authors thank the FIST, Department of Science and Technology (SR/FST/COLLEGE-096/2017), India for financial support and Taif University Researchers Supporting Project number (TURSP-2020/244), Taif University, Ta'if, Saudi Arabia.

\section{REFERENCES}

[1] Yang H, Ye S, Zhou J, Liang T, Frontiers Chem 7, 1 (2019).

[2] Kandasamy S K, Kandasamy K, J Inorg Organomet Polym 28, 559 (2018).

[3] Yi M L, Mei N, Lei Z, Ren J C, Wen Y, Chem European J, 24, 18068 (2018).

[4] Wang Q, Zhou M, Zhang Y et al., J Mater Sci: Mater Electron, 29, 4294 (2019).

[5] Kandasamy S K, Kandasamy K, Int J Electrochem Sci, 14, 4718 (2019).

[6] Murugesan G, Devendran, M, Kandasamy S K, Shanmugam P, Sangavi S, Ragavi V, Roobak S, Int J Electrochem Sci, 15, 4379 (2020).

[7] Kannan K, Murugesan G, Senthil K K, Chandrasekaran A, Effects of Microwave Annealing of Graphene and its Impact on Structural, Electrochemical Performance for Energy Storage. 2018 International Conference on Intelligent Computing and Communication for Smart World (I2C2SW) 241-243.

[8] Chao W, Ye X, Hanwei W, Qingfeng S, J Coll Interface Sci., 528, 349 (2018). 
[9] Sun K, Wang H, Peng H, Wu Y, Ma G, Lei Z, I J Electrochem Sci, 10, 2000 (2015).

[10] Kaippannan S, Nagarajan S, Manickaviasakam K, Marappan S, Chem Select, 2, 11384 (2018).

[11] Gou H, He J, Zhao G, Zhang L, Yang C, Rao H, Ionics 1, 1 (2019).

[12] Ranveera C K, Kahol P K, Ghimire M, Mishra S R, Ram K G, J Carbon Res, 3, 1 (2017).

[13] Ahmed S, Rafat M, Ahmed A, Adv Nat Sci Nanosci Nanotech, 9, 1 (2018).

[14] Dhelipan M, Arunchander A, Sahu A K, Kalpana D, J Saudi Cheml Soc, 21, 487 (2017).

[15] Arie A A, Kristianto H, Suharto I, Halim M, Lee J K, Adv Mater Res, 896, 95 (2014).

[16] Muduli S, Naresh V, Martha S K, J Electrochem Soc, 167, 1 (2020).

[17] Nazish P, Ibrahim A A, Jeong I H, Electrochim Acta, 293, 84 (2019).

[18] Subramani K, Sathish M, Sci Rep, 9, 1 (2019).

[19] Kim J, Shin D, Baek D, Park J, Electron. 8, 1 (2019).

[20] Hsin Y C, Chun P C, Nanomat, 8, 1 (2018).

[21] Lanshu X, Xuji D, Jixin Z, J Electrochem Soc., 165, 2217 (2018).

[22] Zhuangnan L, Srinivas G et al., Energy Storage Mat., 17, 12 (2019).

[23] Teoh K H, Lim C S, Liew C W, Ramesh S, Ramesh S, Ionics, 21, 2061 (2015).

[24] Deraman M, Mohd N N S, Yatim E T B, Awitdrus, Rakhmawati F, Basri N H, Jasmi M R M, Rusli D, Soltaninejad S, Mat Sci Forum. 846, 497 (2018).

[25] Mandal D, Routh P, Mahato K, Nandi K, J Mater Chem A 7, 17547 (2019).

[26] Liyuan Q, Zhiwei H, Shuang L, Shuang L, Zhongyuan L, Enchen J, I J Electrochem Sci, 14, 8907 (2019).

[27] Chaochao X, Fen X, Lixian S, Lizhi C, Fang Y, Huanzhi Z, Erhu Y, Hongliang P, Hailiang C, Yongjin Z, I J Electrochem Sci, 14, 1782 (2019).

[28] Harshini P V S, Saravanathamizhan R, Balasubramanian N, Preparation of Biomass Based Carbon for Electrochemical Energy Storage Application, J Electrochem Sci Tech, 10, 159 (2019).

[29] Jie W, Mi M W, Shao J W, Yun Q L, Shui R L, Yue Y Y, Meng W, Duo W, Bioresources, 14, 3899 (2019).

[30] Yunya Z, Zan G, Ningning S, Xiaodong L, Electrochim Acta, 222, 1257 (2016).

[31] Hui C, Gang W, Long C, Bin D, Feng Y, Nanomater, 8, 1 (2018).

[32] Ghosh S, Santhosh R, Jeniffer S et al., Sci Rep, 9, 1 (2019).
[33] Zequine C, Ranaweera C. K, Wang Z, Singh S, Tripathi P, Srivastava O. N, Gupta B. K, Ramasamy K, Kahol P K, Dvornic P R, Gupta R K, Sci Rep, 6, 1 (2016).

[34] Taer E, Taslim R, Ainil Z, Hartail S D, Mustika W S, Activated Carbon Electrode from banana peel waste for Supercapacitor Application. The 6th International Conference on Theoretical and Applied Physics (The 6th ICTAP) 1-4 (2017).

[35] Liu B, Zhang L, Qi P, Nanomater, 6, 1 (2016).

[36] Hui C, Zhuangzhi Z, Peirong Q, Gang W, Lei S, Feng Y, I J Nanomanufactur, 15, 181 (2019).

[37] Indu K, Sanjeev M, Ashok K S, Kor Chem Eng Res, 56, 694 (2018).

[38] Subramanian V, Cheng L, Stephan A M, Nahm K S, Sabu T, Bingqing W, J Phys Chem C, 111, 7527 (2007).

[39] Yaokang L, Lihua G, Mingxian L, Wei X, Zijie X, Dazhang Z, Dominic S, Wright A, J Power Sour, 209, 152 (2012).

[40] Widiatmoko P et al., J Eng Tech Sci, 48, 597(2016).

[41] Kurniawan W B, Indriawati A, Marina D., Earth Environ Sci., 353, 1 (2019).

[42] Masruroh M R, Dwi S, Fitriani N A, Zainollah A, Rahmah A, Indonesian J App Phy, 7, 1 (2017).

[43] Zhao S, Wang C Y, Chen M M, Wang J, Shi Z Q, J Phy Chem Solids, 70, 1256 (2009).

[44] Qianqian L, Fu L, Li Z, Bradley J N, Sihan Z, Chao M, Xinyong T, Jipeng C, Xiaobin Z, J Power Sour, 207, 199 (2012).

[45] Madhavi Y, Manindra K, Neelam S, Electrochim Acta, 283, 1551 (2018).

[46] Baby K, Madhavi Y, Manindra K, Tuhina T, Neelam S, e-Polym, 19, 453 (2019).

[47] Neelam S, Mater Res Foundations, 61, 121 (2019).

[48] Bo Z, Erlin M, Zhenqian C, I J Electrochem Sci, 13, 2441 (2018)

[49] Adebisi A, Chowdhury Z, Abd H, Sharifah B, Ali M, BioResources, 11, 9686 (2016).

[50] Siburian R, Sihotang H, Raja S, Supeno M, Simanjuntak C, Oriental J Chem, 34, 182 (2018).

[51] Tomul F, Arslan Y, Basoglu F, Babuçcuoğlu Y, Tran H, J Environ Management, 238, 296 (2019).

[52] Domene L D, García Q J, Martin G I, Montalbán M G, Polym, 11, 1 (2019).

[53] Kandasamy S K, Arumugam C, Vadivel L, Ganapathi M, Nattudurai N, Kandasamy K, Int J Emerging Tech, 11,565 (2020). 